\title{
ACCURACY OF FINE NEEDLE ASPIRATION CYTOLOGY IN THE DIAGNOSIS OF NECK MASSES
}

\author{
Mudassar Ahmed Shariff1 ${ }^{1}$, Srinivasa V², Elangovan S3, Manikandan D ${ }^{4}$, Jarvis Raju ${ }^{5}$
}

\section{HOW TO CITE THIS ARTICLE:}

Mudassar Ahmed Shariff, Srinivasa V, Elangovan S, Manikandan D, Jarvis Raju. "Accuracy of Fine Needle Aspiration Cytology in the Diagnosis of Neck Masses". Journal of Evolution of Medical and Dental Sciences 2014; Vol. 3, Issue 09, March 3; Page: 2087-2093, DOI: 10.14260/jemds/2014/2107

\begin{abstract}
OBJECTIVE: Fine Needle Aspiration Cytology is being used as a diagnostic modality for neck masses. This study is done to evaluate the role of Fine Needle Aspiration Cytology in the diagnosis of neck masses. A correlation was done between cytology and histopathology, to assess the accuracy of Fine Needle Aspiration Cytology in the diagnosis of neck masses. SETTING: Department of Otorhinolaryngology, Vinayaka Mission's Medical College and Hospital, Karaikal, Pondicherry (U.T). DESIGN: A Prospective study. MATERIALS AND METHODS: Data for this study was collected from patients attending OPD and admitted in Vinayaka Mission's Hospital, Department of Otorhinolaryngology, attached to Vinayaka Mission's Medical College, Karaikal. 100 patients presenting with neck masses to our institution between September 2011 and August 2013 were included in the study. After a detailed clinical examination, relevant investigations and a valid informed consent, Fine Needle Aspiration Cytology of the neck swelling was performed, followed by biopsy and histopathological examination of the neck swelling. The result of Fine Needle Aspiration Cytology was correlated with result of Histopathological examination of neck swelling. STATISTICAL ANALYSIS USED: The result of this study was calculated by using the method of Galen and Gambino for substantiating the correlation. RESULTS: The histopathological correlation of Fine Needle Aspiration Cytology in our study was $92 \%$. The sensitivity, specificity and efficiency of Fine Needle Aspiration Cytology in our study were $87.5 \%, 100 \%$ and $98 \%$ respectively. CONCLUSION: Fine Needle Aspiration Cytology is an excellent first line method for investigating patients presenting with neck masses. Since the masses of the neck are easily accessible, Fine Needle Aspiration Cytology is a diagnostic procedure which suits well for such a situation.
\end{abstract}

KEYWORDS: Fine Needle Aspiration Cytology, Neck mass, Histopathology.

INTRODUCTION: A patient presenting with a mass in the neck is a common occurrence in clinical practice. Neck masses may be due to congenital, inflammatory, benign or malignant neoplastic conditions. Enlargement of lymph nodes, thyroid gland, parotid glands, submandibular glands are commonly responsible for neck masses. Traditionally, surgical biopsy and its histopathological study has remained the main stay for the diagnosis and management of the neck mass. Here the whole tissue is available for examination under microscope. Of late, a parallel but separate discipline has arisen for the diagnosis of neck masses. It is called as Fine Needle Aspiration Cytology (FNAC). The FNAC involves study of cells obtained by fine needle under vacuum. Unlike biopsy, the whole tissue is not available for microscopic examination. Only cells are available for microscopic examination. The present study was done to evaluate the accuracy of FNAC in the diagnosis of head and neck masses.

MATERIALS AND METHODS: Data for this study was collected from patients attending OPD and admitted in Vinayaka Mission's Hospital, Department of Otorhinolaryngology attached to Vinayaka Mission's Medical College, Karaikal, Pondicherry (U.T). This is a prospective study. Patients presenting with neck swelling were enrolled in this study. Relevant information regarding patient data, history and clinical findings were recoded. Basic hematological and other relevant 
investigations were done. Consent from all the patients was taken prior to performing fine needle aspiration cytology.

The procedure was explained to the patient. FNAC was done as an outpatient procedure. Under aseptic precautions, aspirate was obtained using a 23 gauge disposable needle and a $10 \mathrm{ml}$ disposable syringe attached to it. After obtaining the aspirate, pressure was applied at the aspiration site and an antiseptic solution was applied. Fine needle aspiration cytology report was obtained after microscopic examination of the aspirate. Depending on the fine needle aspiration cytology report, if further relevant investigations were necessary, they were done. Biopsy of the neck mass was performed after obtaining consent from patients.

The result of fine needle aspiration cytology was correlated with result of histopathological examination of excision or incision biopsy of neck mass. Only patients who underwent biopsy were selected for the study. Results were expressed in terms of percentage. The result of this study was calculated by using the method of Galen and Gambino for substantiating the correlation.

RESULTS: A total of 100 cases presenting with neck masses were studied. The age incidence ranged from 1 year to 68 years. The highest incidence of neck masses was between 21-30 years age group (35\%)and the lowest incidence was between 61-70 years age group (1\%). 68\% of the patients were females and $32 \%$ were males, the male to female ratio being 1:2.12.

Out of 100 cases, 92 cases had a positive correlation of FNAC with histopathological examination. Therefore the diagnostic accuracy of fine needle aspiration cytology in our study was $92 \%$.

The sensitivity, specificity and efficiency of FNAC in detecting malignant lesions in our study were $87.5 \%, 100 \%$ and $98 \%$ respectively. Positive predictive value and Negative predictive value of FNAC in detecting malignancy was $100 \%$ and $97.67 \%$ respectively.

Amongst 34 cases of lymph node masses, 31 cases were correctly diagnosed using FNAC with a diagnostic accuracy of $91.1 \%$. Amongst 32 cases of thyroid masses, 29 cases were correctly diagnosed using FNAC with a diagnostic accuracy of $90.6 \%$. Amongst 16 cases of salivary gland masses, 14 cases were correctly diagnosed using FNAC with a diagnostic accuracy of 87.5\%.With respect to congenital cysts, all 14 cases were correctly diagnosed using FNAC with a diagnostic accuracy of $100 \%$.

The immediate post-procedure period was uneventful and none of the patients had postprocedure complications or complaints following FNAC. 


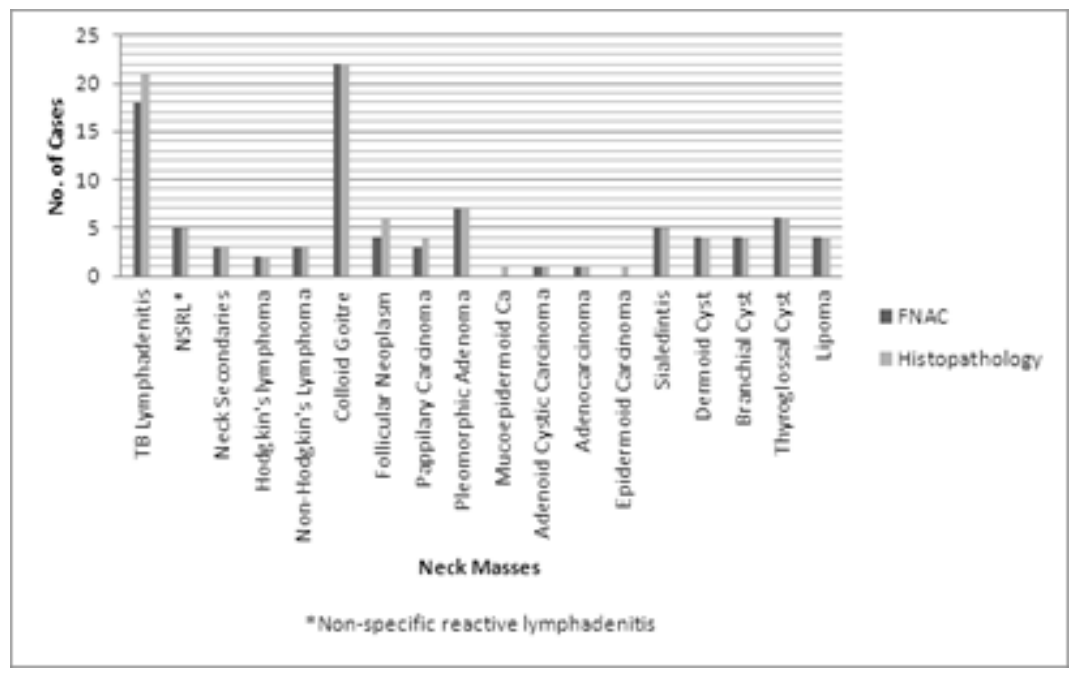

Graph: Histopathological Correlation of FNAC

\begin{tabular}{|l|c|c|}
\hline \multicolumn{1}{|c|}{ Neck Masses } & $\begin{array}{c}\text { Total } \\
\text { (as per Histopathology report) }\end{array}$ & FNAC was correct in \\
\hline Tuberculous lymphadenitis & 21 & 18 \\
\hline $\begin{array}{l}\text { Non-specific reactive } \\
\text { lymphadenitis }\end{array}$ & 5 & 5 \\
\hline Neck Secondaries & 3 & 3 \\
\hline Hodgkin's lymphoma & 2 & 2 \\
\hline Non-Hodgkin's Lymphoma & 3 & 3 \\
\hline Colloid Goitre & 22 & 22 \\
\hline Follicular Adenoma & 6 & 4 \\
\hline Papillary Carcinoma & 4 & 3 \\
\hline Pleomorphic Adenoma & 7 & 7 \\
\hline Mucoepidermoid Carcinoma & 1 & 0 \\
\hline Adenoid Cystic Carcinoma & 1 & 1 \\
\hline Adenocarcinoma & 1 & 1 \\
\hline Epidermoid Carcinoma & 5 & 0 \\
\hline Sialedintis & 4 & 5 \\
\hline Dermoid Cyst & 4 & 4 \\
\hline Branchial Cyst & 6 & 4 \\
\hline Thyroglossal Cyst & $\mathbf{1 0 0}$ & 6 \\
\hline Lipoma Total & Table 1: Histopathological correlation of FNAC \\
\hline & & $\mathbf{9 2}$ \\
\hline \multicolumn{1}{|c|}{} & & 4 \\
\hline
\end{tabular}




\begin{tabular}{|c|c|c|c|c|}
\hline & \multicolumn{2}{|c|}{ Histopathological Examination } & \multirow{2}{*}{ Total } \\
\hline & & Malignant & Benign & \\
\hline \multirow{2}{*}{$\begin{array}{l}\text { Fine Needle } \\
\text { Aspiration Cytology (FNAC) }\end{array}$} & Malignant & $\begin{array}{c}14 \\
\text { True Positive (TP) }\end{array}$ & $\begin{array}{c}0 \\
\text { False Positive(FP) }\end{array}$ & 14 \\
\hline & Benign & $\begin{array}{c}2 \\
\text { False Negative (FN) }\end{array}$ & $\begin{array}{c}84 \\
\text { True Negative(TN) }\end{array}$ & 86 \\
\hline \multicolumn{2}{|l|}{ Total } & 16 & 84 & 100 \\
\hline \multicolumn{5}{|c|}{ Sensitivity of FNAC $=\frac{\mathrm{TP}}{\mathrm{TP}+\mathrm{FN}} \times 100=\frac{14}{14+2} \times 100=87.5 \%$} \\
\hline \multicolumn{5}{|c|}{ Specificity of FNAC $=\frac{\mathrm{TN}}{\mathrm{TN}+\mathrm{FP}} \times 100=\frac{84}{84+0} \times 100=100 \%$} \\
\hline \multicolumn{5}{|c|}{ Efficiency of FNAC $=\frac{\mathrm{TP}+\mathrm{TN}}{\mathrm{TP}+\mathrm{FP}+\mathrm{FN}+\mathrm{TN}} \times 100=\frac{14+84}{100} \times 100=98 \%$} \\
\hline \multicolumn{5}{|c|}{ Positive predictive value $=\frac{\mathrm{TP}}{\mathrm{TP}+\mathrm{FP}} \times 100=\frac{14}{14+0} \times 100=100 \%$} \\
\hline \multicolumn{5}{|c|}{ Negative predictive value $=\frac{\mathrm{TN}}{\mathrm{TN}+\mathrm{FN}} \times 100=\frac{84}{84+2} \times 100=97.6 \%$} \\
\hline
\end{tabular}

DISCUSSION: Otolaryngologists frequently encounter neck masses presenting to them in all age groups. Along with patient details, a detailed history including the site, size and duration of the neck mass should be obtained and a thorough clinical examination should be performed. Inflammatory and infectious causes of neck masses such as cervical lymphadenitis are common in young adults. Congenital masses such as cystic hygroma, branchial anomalies, thyroglossal duct cysts should also be considered in the differential diagnosis. In adult patients, thyroid swellings are most likely to be present in females and neoplasms are more common in males.

Neck masses are easily accessible as a result of relatively superficial locations where they are often palpable ${ }^{1}$. Hence neck masses offer an accessible site for fine needle aspiration cytology. Because of the variety of tissues present in the neck a wide range of lesions can be seen in this region. Close co-operation between the cytologist and the clinician is necessary to be sure of the anatomical relations of the lesion to be aspirated. FNAC is being used all over the world and even in our country as one of the investigations for palpable masses of neck, as it helps in diagnosis and to proceed with further investigations and treatment. ${ }^{2}$

The diagnostic accuracy of Fine Needle Aspiration Cytology in our study was $92 \%$ which is in accordance with other studies. ${ }^{3,4}$ The sensitivity of Fine Needle Aspiration Cytology for the detection of malignancy in our study was $87.5 \%$, the specificity (accuracy for absence of malignancy) was 
$100 \%$ and efficiency was $98 \%$. Positive predictive value was $100 \%$; negative predictive value was $97.67 \%$. This is similar to other studies. ${ }^{4,5}$

The diagnostic accuracy of Fine Needle Aspiration Cytology for lymph nodes in our study was $94 \%$, which is similar to a study by Young JE et al who got a diagnostic accuracy of $94 \%{ }^{4}$.In the case of lymphadenopathy, FNAC is an initial step in evaluation and a specific diagnosis is obtained $82 \%$ to $96 \%$ of times ${ }^{1}$. Accuracy of FNAC for diagnosis of Tuberculous lymphadenitis was $85.7 \%$ in our study, which is similar a study by Bandhopadhyay SN et $\mathrm{al}^{6}$. All cases of Non-Specific Reactive Lymphadenitis were correctly diagnosed giving 100\% accuracy, which is similar to a study by Tarantino DR et al 7 . All 3 cases of secondaries in the neck were correctly diagnosed with $100 \%$ accuracy, which is similar to other studies ${ }^{5,7}$. Fine needle aspiration cytology has an important role in the identification of metastatic disease ${ }^{8}$.

Upper cervical lymph nodes are a common site of metastases from lesions of oral cavity, oropharynx, larynx and nasopharynx. Gastrointestinal malignancies may metastasize to lower cervical and supraclavicular lymph nodes ${ }^{8}$. Diagnosis of metastatic disease by fine needle aspiration cytology can narrow the search for primary lesion. Fine needle aspiration cytology helps avoid unnecessary incision in the neck which would interfere with definitive neck dissection or provide a route for the direct spread of disease in cases of malignancy. We had 5 cases of lymphoma in this study all of which were correctly diagnosed, giving a diagnostic accuracy of $100 \%$, which is similar to other studies. ${ }^{7,9}$

FNAC of thyroid has become the diagnostic keystone for the evaluation of thyroid nodules. It is a very useful investigation in most of the thyroid lesions, particularly in solitary thyroid nodules, where it has been recommended as investigation of first choice. Fine needle aspiration cytology in cases of thyroid lesions is a simple, cost effective procedure with minimal complications ${ }^{10}$. Accuracy of FNAC for diagnosis of thyroid masses was $90.6 \%$ in our study, which is similar to a study by Vojdodich SM et al who got a diagnostic accuracy of $86 \% 11$. All cases of Colloid goiters were correctly diagnosed, giving $100 \%$ accuracy, which is similar to a study by Jayaram $\mathrm{G}$ et al ${ }^{12}$. FNAC gave a diagnostic accuracy of $66.6 \%$ in cases of Follicular adenoma and $75 \%$ in cases of Papillary Carcinoma, which is similar to a study by Sangalli G et al.13

The diagnostic accuracy of FNAC in cases of salivary gland masses was $87.5 \%$, which is similar to a study by Zurrida $S$ et al who got a diagnostic accuracy of $87 \%^{14}$. All cases of Pleomorphic adenoma and Submandibular Sialadenitis were correctly diagnosed using FNAC with 100\% diagnostic accuracy which is similar to a study by Viguer JM et al ${ }^{15}$. There were other cases of Pleomorphic adenoma of the submandibular salivary gland, malignant parotid masses like mucoepidermoid carcinoma, adenoid cystic carcinoma, adenocarcinoma in which comparison was not possible because of small sample size.

All the cases of congenital neck masses and lipoma were correctly diagnosed using FNAC in our study with $100 \%$ diagnostic accuracy, which is similar to a study by Dejmek A et al ${ }^{16}$.

CONCLUSION: From this study it can be concluded that fine needle aspiration cytology is a relatively atraumatic, well tolerated procedure which can be readily performed in outpatient set up. This technique is an excellent first line of investigation for the patients presenting with neck masses. Since the masses of the neck are easily accessible, FNAC is a diagnostic procedure, which suits well for such a situation. FNAC has a high accuracy rate; this technique is simple, rapid, safe and painless. It can be 
especially valued because it is an out-patient procedure; done without prior preparation or anesthesia. Both, FNAC procedure and interpretation are quick; it is a cost-contained procedure. It is eminently suitable for all age groups. The co-operation from the patients for the procedure is excellent. In the neck, it obviates the need for an excision biopsy in benign conditions, thereby reducing the chances of an ugly scar in the exposed area. It is also an essential investigation for the detection of malignant conditions arising in neck. The chances of complications, such as infection, hemorrhage are almost nil.

However, it must never be thought as a replacement for histopathological diagnosis in all cases. The two have to complement each other, along with the other newer diagnostic techniques for a diagnosis to be infallible and accurate for further management.

\section{REFERENCES:}

1. Amedee RG, Dhurandhar NR. Fine Needle Aspiration Biopsy. Laryngoscope.2001 Sept.; 111:1551-1557.

2. Platt JC, Davidson D, Nelson CL, Wisberger E. Fine Needle Aspiration Biopsy. An analysis of 89 head and neck cases. J Oral Maxillofacial Surg1990; 48(7):702-706.

3. Tilak V, Dhaded AV, Jain R. Fine needle aspiration cytology of head and neck masses. Indian J Pathol Microbiol. 2002 Jan.; 45(1):23-29.

4. Young JE, Archibald SD, Schier KJ. Needle aspiration cytologic biopsy in head and neck masses. Am J Surg 1981; 142:484-489.

5. Fernandes H, D'Souza CRS, Thejaswini BN. The role of fine needle aspiration cytology in palpable head and neck masses. J Clinical Diagnostic Research.2009 Oct.;3(5):1719-1715.

6. Bandhopadhyay SN, Roy KK, Dasgupta A, Ghosh RN. Role of Fine needle aspiration cytology in the diagnosis of cervical lymphadenopathy. Indian J Otolarygol Head Neck Surg 1996 Oct.Dec.;48(4):289-293.

7. Tarantino DR, Mc Henry CR, Strickland T, Khiyami A. The role of fine needle aspiration biopsy and flow cytometry in the evaluation of persistent neck adenopathy. Am J Surg 1998;176:413417.

8. Patt BS, Schaefer SD, Vuitch F. Role of fine needle aspiration in the evaluation of neck masses. Med Clin North Am 1993;77:611-623.

9. Daskalopoulou D. Fine needle aspiration cytology in tumours and tumour like conditions of oral and maxillofacial region. Diagnostic Reliability and Limitations. Cancer 1997;81(4):238-252.

10. Ravichander PK, Smile SR, Verma SK. Effectiveness of fine needle aspiration cytology in thyroid lesions in contrast with histopathology. J Cytology2000;17(1):33-38.

11. Vojdodich SM. Accuracy of fine needle aspiration in the preoperative diagnosis of thyroid neoplasm. J Otolaryngol Head Neck Surg 1994;23:360-365.

12. Jayaram G, Basu D. Cytology in the diagnosis of thyroid lesions. J Assoc Physicians India 1993 March;41(3):164-169.

13. Sangalli G, Serrio G, Zampatti C, Belloti M, Lomuscio G. Fine needle aspiration cytology of the thyroid: a comparison of 5469 cytological and final histological diagnosis. Cytopathol 2006;17:245-250.

14. Zurrida S, Allosio S, Tradati N, Bartoli C, Chiesa F, Pillotti S. Fine needle aspiration of parotid masses. Cancer 1993;72(8):2306-2311. 


\section{ORIGINAL ARTICLE}

15. Viguer JM, Vicandi B, Jimenez-Hefferman JA, Lopez-Ferrer P, Linures MA. Fine needle aspiration cytology of pleomorphic adenoma. An analysis of 212 cases. Acta Cytologica 1997;41(3):786794.

16. Dejmek A, Lindholmk. Fine needle aspiration biopsy of cystic lesions of the head and neck excluding the thyroid. Acta Cytologica 1990; 34(3):443-448.

\section{AUTHORS:}

1. Mudassar Ahmed Shariff

2. Srinivasa $\mathrm{V}$.

3. Elangovan S.

4. Manikandan D.

5. Jarvis Raju

\section{PARTICULARS OF CONTRIBUTORS:}

1. Assistant Professor, Department of ENT, Vinayaka Mission's Medical College, Karaikal.

2. Professor and HOD, Department of ENT, Vinayaka Mission's Medical College, Karaikal.

3. Professor, Department of ENT, Vinayaka Mission's Medical College, Karaikal.

4. Post Graduate Student, Department of ENT, Vinayaka Mission's Medical College, Karaikal.
5. Post Graduate Student, Department of ENT, Vinayaka Mission's Medical College, Karaikal.

\section{NAME ADDRESS EMAIL ID OF THE} CORRESPONDING AUTHOR:

Dr. Mudassar Ahmed Shariff,

Assistant professor, Department of ENT,

Vinayaka Mission's Medical College,

Keezhakasakudimedu,

Kottucherry Post Office, Karaikal - 609609,

Pondicherry (U. T).

E-mail: mudassarshariff@gmail.com

Date of Submission: 01/02/2014.

Date of Peer Review: 03/02/2014.

Date of Acceptance: 13/02/2014.

Date of Publishing: 24/02/2014. 